\title{
Implementasi Algoritma Shuffle Random pada Pembelajaran Panca Indra Berbasis Android
}

\section{(Implementation of Random Shuffle Algorithm on Five Senses Learning Based on Android)}

\author{
Amelia Yusnita ${ }^{1}$, Tabrani Rija'i ${ }^{2}$ \\ ${ }^{1}$ amelia@wicida.ac.id \\ ${ }^{2}$ tabrani@wicida.ac.id
}

${ }^{1,2}$ Sistem Informasi-STMIK Widya Cipta Dharma

Jl.M.Yamin No 25, Samarinda, Kalimantan-timur

\begin{abstract}
Abstrak - Media pembelajaran sangat menarik untuk dikembangkan, kelebihan utamanya adalah visualisasi yang digunakan sebagai salah satu media edukasi pembelajaran. Berdasarkan pola yang dimiliki oleh permainan tersebut, pemain dituntut untuk belajar sehingga dapat menyelesaikan permasalahan yang ada. Pembelajaran panca indra merupakan sebuah media pembelajaran yang memiliki soal-soal latihan. Dalam permainan ini pemain harus menjawab pertanyaan yang tersedia dimana pemain harus dengan benar dan teliti untuk menjawab pertanyaan soal tersebut. Untuk teknik pengacakan posisi menggunakan algoritma shuffle random, dengan tujuan membuat susunan posisi soal menjadi teracak, dan pemain tidak bisa menghapal soal yang dikerjakan sebelumnya. Alat bantu perancangan sistem yang digunakan adalah flowchart, dalam pembuatannya menggunakan software aplikasi SwishMax4. Dan hasilnya dikemas menjadi media pembelajaran yang dapat dimainkan untuk siswa-siswi tingkat SD, sebagai alternatif sistem pembelajaran yang efektif dan memberikan pengetahuan lebih bagi pengguna.
\end{abstract}

\section{Kata kunci-Panca Indra, pembelajaran, shuffle random}

Abstract: Learning media is very interesting to develop, the main advantage is visualization that is used as one of the learning media for learning. Based on the patterns possessed by the game, players are required to learn so that they can solve existing problems. Sensory learning is a learning media that has practice questions. In this game, the player must answer the available questions where the player must be correct and careful to answer the question. For position randomization techniques using random shuffle algorithm, with the aim of making the composition of the position of the problem becomes randomized, and the player cannot memorize the questions that were worked before. The system design tool used is the flowchart, in making it using the SwishMax4 application software. And the results are packaged into learning media that can be played for elementary school students, as an effective alternative learning system and provide more knowledge for users.

Keywords-Five Senses, learning, shuffle random

\section{PENDAHULUAN}

Untuk menambah pengetahuan dalam mengenal panca indra, anak-anak harus mengetahui organ tubuh apa saja yang termaksud di dalam panca indra yang dimiliki oleh manusia. Agar Anak-anak lebih tertarik untuk belajar, diperlukan metode dan desain yang mempermudah dalam penyampaian ilmu pengetahuian yang berhubungan dengan panca indra .

Berdasarkan permasalahan diatas maka dibuatlah rancangan baru pengenalan panca indra dengan media pembelajaran, yaitu " penerapan metode shuffle random pada aplikasi pembelajaran panca indra berbasis android. Bentuk media pembelajaran berupa gambar dan suara yang menjelaskan dari panca indra tersebut, dan pengguna dapat berlatih mengerjakan soal latihan yang teracak secara random.

\section{A. Algoritma Shuffle Random}

Shuffle random adalah pengacakan urutan indeks dari sebuah record atau array. Pengacakan ini diibaratkan pengocokan pada dek kartu, semua kartu dikocok sehingga susunannya teracak. Contoh lain misalkan A adalah array $5 \times 1, A=\left[\begin{array}{lllll}1 & 2 & 3 & 4 & 5\end{array}\right]$ maka proses shuffle random akan mengacak susunan indek dari array A menjadi A1 = [ $\left.\begin{array}{lllll}5 & 1 & 3 & 2 & 4\end{array}\right]$ ataupun menjadi susunan array yang lain. Dalam bahasa pemrograman fungsi shuffle random tidak hanya dapat mengacak angka, tetapi juga dapat mengacak array string ataupun campuran string dan angka [1]. 
1) Pengkodean Pengacakan Shuffle: Gambar 1, merupakan tahap kedua penggunaan fungsi shuffle random untuk mengacak susuan dari array A.

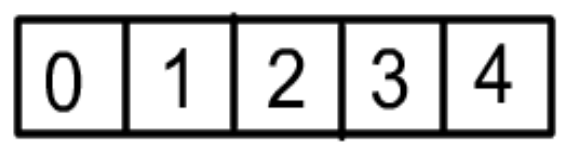

Gambar.1 Array arena yang belum teracak

Pada tahap ini dilakukan deklarasi nilai array seperti pada contoh script dibawah ini :

$\mathrm{A}=$ new Array $(0,1,2,3,4$,

Dimana nilai indek array yang pertama (indeks ke0 ) adalah 0 , dan indeks terakhir adalah 4.

2) Pengkodean Pengacakan Shuffle: Gambar 2, merupakan tahap kedua penggunaan fungsi shuffle random untuk mengacak susunan dari array $\mathrm{A}$.

\section{$\mathrm{A} \leftarrow$ random.shuffle $(\mathrm{A})$}

Fungsi di atas membuat nilai array A yang pada mulanya $\mathrm{A}=[1,2,3,4]$ dapat teracak menjadi $\mathrm{A}=$ $[4,2,3,1]$ ataupun menjadi susunan array yang lain.

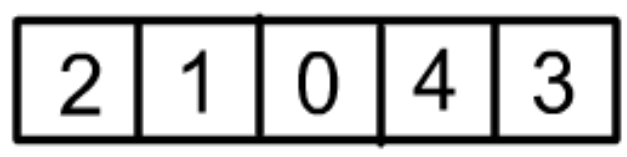

Gambar.2 Array arena yang sudah teracak

\section{B. Pembelajaran}

Pembelajaran adalah usaha - usaha yang terencana dalam memanipulasi sumber - sumber belajar agar terjadi proses belajar dalam diri peserta didik. Dalam proses pembelajaran, terjadi proses interaksi antara peserta didik dengan pendidik dan sumber belajar pada suatu lingkungan belajar. Pembelajaran merupakan bantuan yang diberikan pendidik agar dapat terjadi proses perolehan ilmu dan pengetahuan dan pembentukan sikap pada peserta didik. Dengan kata lain, pembelajaran adalah suatu proses membantu peserta didik agar dapat belajar dengan baik [2].

Pembelajaran merupakan proses pencarian ilmu pengetahuan secara aktif atau proses perumusan ilmu, bukan proses pengungkapan ilmu semata [3].

\section{Panca Indra}

Analisis ini menggunakan acuan dasar berupa gabungan dua teori dari Deplasez dan Andrea dalam buku Constructing Architecture serta Malnar dan Vodvarka dalam buku Sensory Design terkait panca indra dan aspek interior yang ditangkap oleh panca indra. Panca indra dan beberapa aspek yang dipersepsi berdasarkan panca indra meliputi [4], [5].

1) Visual (mata): Ornament, cahaya, warna, dan materialitas yang bersifat abstrak ataupun nyata.
2) Perabaan (kulit):Tekstur dan sifat material basah, kering, panas, dingin, termasuk suhu ruangan.

3) Pendengaran (telinga): Suara (musik, kebisingan, dan background noises).

4) Penciuman (hidung): Bau atau aroma.

5) Rasa (lidah): Segala sesuatu yang dikecap, dirasakan oleh lidah, atau dikonsumsi.

\section{Android}

Android adalah sebuah system operasi untuk perangkat mobile berbasis linux yang mencakup system operasi, middleware, dan aplikasi. Android menyediakan platform terbuka bagi para pengembang untuk menciptakan aplikasi mereka [6].

\section{METODE}

Metodologi pengembangan multimedia terdiri dari enam tahap. Yaitu concept (pengonsepan), design (pendesainan), materialcollecting (pengumpulan materi), assembly (pembuatan), testing (pengujian), dan distribution (pendistribusian) [7]. Keenam tahap ini tidak dapat bertukar posisi. Meskipun begitu, tahap concept memang harus menjadi hal yang pertama kali dikerjakan dapat dilihat pada Gambar 3.

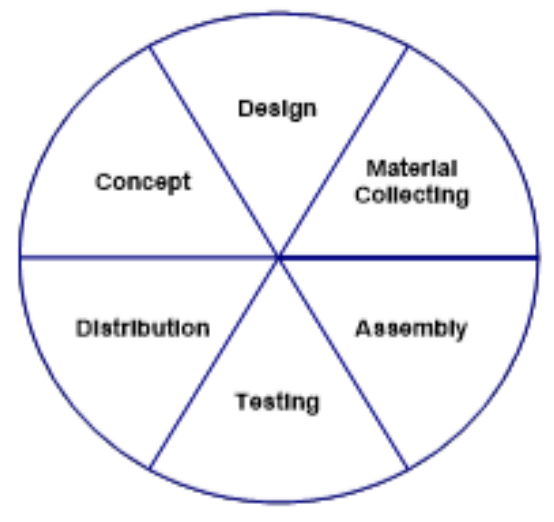

Gambar.3 Tahapan Pengembangan Multimedia

Tahapan pengembangan multimedia meliputi [8], [9]:

1) Concept: Dalam tahapan concept, ditentukan target pengguna aplikasi ini adalah siswa-siswi sekolah dasar. Aplikasi ini berfungsi sebagai pengenalan konsep nama dan bagian tubuh pada manusia yang termasuk dalam panca indra. Konsep dasar aplikasi ini adalah memiliki dua menu pilihan utama yaitu pembelajaran, dan latihan soal. Dalam permainan ini memiliki aturan main yaitu pemain harus menebak jawaban benar dari 5 soal yang tersedia sesuai dengan soal yang diberikan, jika pemain memilih jawaban yang benar maka pada akhir permainan nilai yang di peroleh tinggi sedangkan, 
jika pemain memilih jawaban yang salah maka nilai pada akhir permainan rendah.

2) Design: Dalam tahap ini, membuat design secara rinci mengenai struktur aplikasi yang akan dibuat. Tahapan design ini merupakan tahap membuat perancangan sebuah aplikasi dengan mengacu pada hasil analisis kebutuhan dari tahapan concept sebelumnya. Pada tahap ini perancangan model sistem aplikasi menggunakan flowchart dan dalam pembuatan media ini semua desain ditampilkan mulai dari menu utama, menu pembelajaran, dan menu latihan.

3) Material Collecting: Pengumpulan bahan merupakan tahap ketiga setelah menentukan desain media pembelajaran, bahan yang digunakan untuk mendukung dalam pembuatan media pembelajaran, yaitu : suara, dan gambar,

4) Assembly: Tahap assembly (pembuatan) merupakan tahapan pembuatan aplikasi dibuat atau diintegrasikan. Dalam pembuatan aplikasi ini menggunakan software SwishMax4 yang dibuat berdasarkan flowchart yang berasal dari tahap desain.

5) Testing : Tahap testing dilakukan setelah tahap assembly dan seluruh bahan telah dimasukkan dan aplikasi telah selesai. Tujuan dilaksanakannya pengujian ini untuk menentukan kesalahan dan juga untuk memastikan bahwa aplikasi yang dibuat telah sesuai dengan yang diinginkan. Pengujian ini dilakukan dengan pengujian blackbox.

6) Distribution : Pada tahap ini aplikasi akan dikemas menjadi aplikasi pembelajaran yang bersifat Universal Windows Platform. Tahap distribusi juga merupakan tahap evaluasi terhadap suatu produk multimedia, diharapkan akan dapat dikembangkan dalam bentuk sistem multimedia yang lebih baik di kemudian hari.

\section{HASIL DAN PEMBAHASAN}

\section{A. Flowchart}

Pada gambar 4, menjelaskan tahapan proses suatu sistem, dimana flowchart dimulai dengan tampilan menu utama, didalam tampilan menu utama, terdapat halaman pembelajaran, didalam halaman tersebut, pemain dapat langsung memilih pilihan panca indra, yaitu mata, jika pilihan benar maka akan tampil keterangan atau penjelasan tentang mata, jika tidak akan tampil panca indra yang lain.

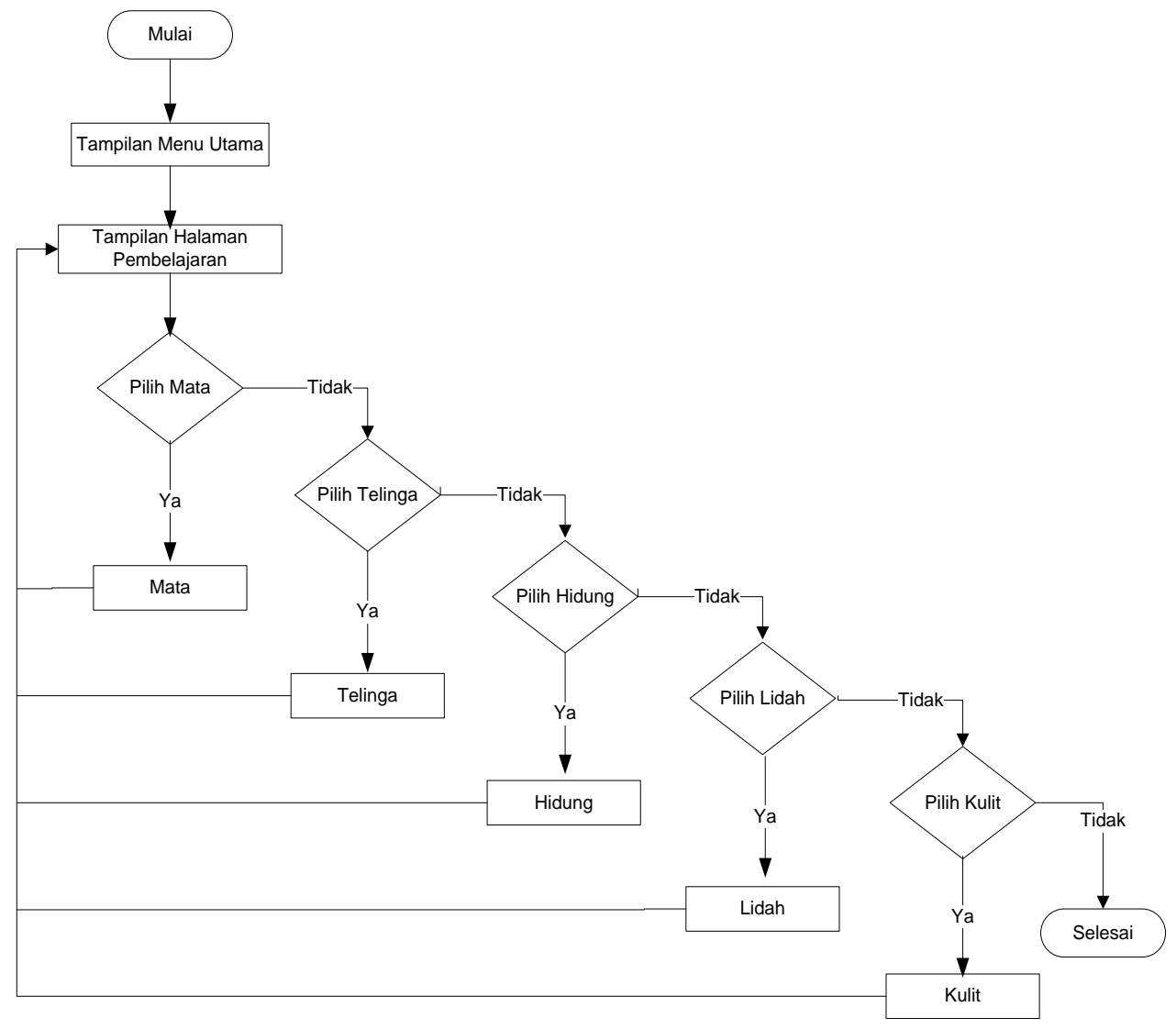

Gambar.4 Flowchart pembelajaran panca indra 


\section{B. Algoritma Shuffle Random}

Shuffle Random adalah pengacakan urutan indeks dari sebuah record atau array. Pengacakan ini diibaratkan pengocokan pada dek kartu, dimana semua kartu dikocok sehingga susunannya teracak. Contoh lain misalkan A adalah array $20 \times 1, A=\left[\begin{array}{llllll}1 & 2 & 3 & 4 & 5 & 6\end{array}\right.$ $891011121314151617181920]$ maka proses Shuffle Random akan mengacak susunan indek dari array A menjadi $\mathrm{A}^{1}=\left[\begin{array}{lll}5 & 132476910813161912\end{array}\right.$ 15111418191720 ] ataupun menjadi susunan array yang lain. Dalam bahasa pemrograman fungsi Shuffle
Random tidak hanya dapat mengacak angka, tetapi juga dapat mengacak array string ataupun campuran string dan angka [10].

Untuk menerapkan pengacakan posisi soal dengan system Shuffle Random dilakukan dengan beberapa tahapan berikut :

1) Menentukan jumlah soal : Gambar 5 adalah posisi soal yang belum teracak sehingga soal masih berurutan.

\begin{tabular}{|c|c|c|c|c|c|c|c|c|c|}
\hline $\begin{array}{c}\text { Soal } \\
1\end{array}$ & $\begin{array}{c}\text { Soal } \\
2\end{array}$ & $\begin{array}{c}\text { Soal } \\
3\end{array}$ & $\begin{array}{c}\text { Soal } \\
4\end{array}$ & $\begin{array}{c}\text { Soal } \\
5\end{array}$ & $\begin{array}{c}\text { Soal } \\
6\end{array}$ & $\begin{array}{c}\text { Soal } \\
7\end{array}$ & $\begin{array}{c}\text { Soal } \\
8\end{array}$ & $\begin{array}{c}\text { Soal } \\
9\end{array}$ & $\begin{array}{c}\text { Soal } \\
10\end{array}$ \\
\hline $\begin{array}{c}\text { Soal } \\
11\end{array}$ & $\begin{array}{c}\text { Soal } \\
12\end{array}$ & $\begin{array}{c}\text { Soal } \\
13\end{array}$ & $\begin{array}{c}\text { Soal } \\
14\end{array}$ & $\begin{array}{c}\text { Soal } \\
15\end{array}$ & $\begin{array}{c}\text { Soal } \\
16\end{array}$ & $\begin{array}{c}\text { Soal } \\
17\end{array}$ & $\begin{array}{c}\text { Soal } \\
18\end{array}$ & $\begin{array}{c}\text { Soal } \\
19\end{array}$ & $\begin{array}{c}\text { Soal } \\
20\end{array}$ \\
\hline
\end{tabular}

Gambar.5 assembly posisi soal yang belum teracak

2) Jumlah soal yang telah teracak : Gambar 6 adalah gambar posisi soal yang sudah teracak sehingga soal sudah tak berurutan.

\begin{tabular}{|c|c|c|c|c|c|c|c|c|c|}
\hline $\begin{array}{c}\text { Soal } \\
3\end{array}$ & $\begin{array}{c}\text { Soal } \\
7\end{array}$ & $\begin{array}{c}\text { Soal } \\
5\end{array}$ & $\begin{array}{c}\text { Soal } \\
8\end{array}$ & $\begin{array}{c}\text { Soal } \\
1\end{array}$ & $\begin{array}{c}\text { Soal } \\
6\end{array}$ & $\begin{array}{c}\text { Soal } \\
4\end{array}$ & $\begin{array}{c}\text { Soal } \\
2\end{array}$ & $\begin{array}{c}\text { Soal } \\
17\end{array}$ & $\begin{array}{c}\text { Soal } \\
9\end{array}$ \\
\hline $\begin{array}{c}\text { Soal } \\
13\end{array}$ & $\begin{array}{c}\text { Soal } \\
16\end{array}$ & $\begin{array}{c}\text { Soal } \\
12\end{array}$ & $\begin{array}{c}\text { Soal } \\
14\end{array}$ & $\begin{array}{c}\text { Soal } \\
15\end{array}$ & $\begin{array}{c}\text { Soal } \\
11\end{array}$ & $\begin{array}{c}\text { Soal } \\
20\end{array}$ & $\begin{array}{c}\text { Soal } \\
19\end{array}$ & $\begin{array}{c}\text { Soal } \\
10\end{array}$ & $\begin{array}{c}\text { Soal } \\
18\end{array}$ \\
\hline
\end{tabular}

Gambar.6 Posisi Soal Sudah Teracak

\section{Tampilan Antarmuka}

Pada tahap ini akan diperlihatkan hasil dari perancangan antarmuka yang telah diimplementasikan ke dalam program.

1) Menu Utama : merupakan tampilan utama dari media pembelajaran disaat pemain baru memasuki sistem. Terdapat tampilan menu Button dari media pembelajaran panca indra. Setiap tombol pada scene menu utama memiliki fungsi masing-masing dapat dilihat pada Gambar 7.

2) Menu Pembelajaran : Pembelajaran, adalah dimana user dapat melihat, memahami dan mempelajari isi materi yang ada, sehingga memudahkan user dalam menjawab pertanyaan yang di berikan pada menu latihan soal nantinya. Ada 6 tombol yang bisa di pilih di menu pembelajaran yang pertama klik mata untuk masuk ke pembelajaran mata, yang kedua hidung untuk masuk ke pembelajaran hidung, yang ketiga telinga untuk masuk ke pembelajaran telinga, yang keempat kulit untuk masuk ke pembelajaran kulit, yang kelima lidah untuk masuk ke pembelajaran lidah dan yang terakhir kembali untuk ke menu utama dapat dilihat pada Gambar 8.

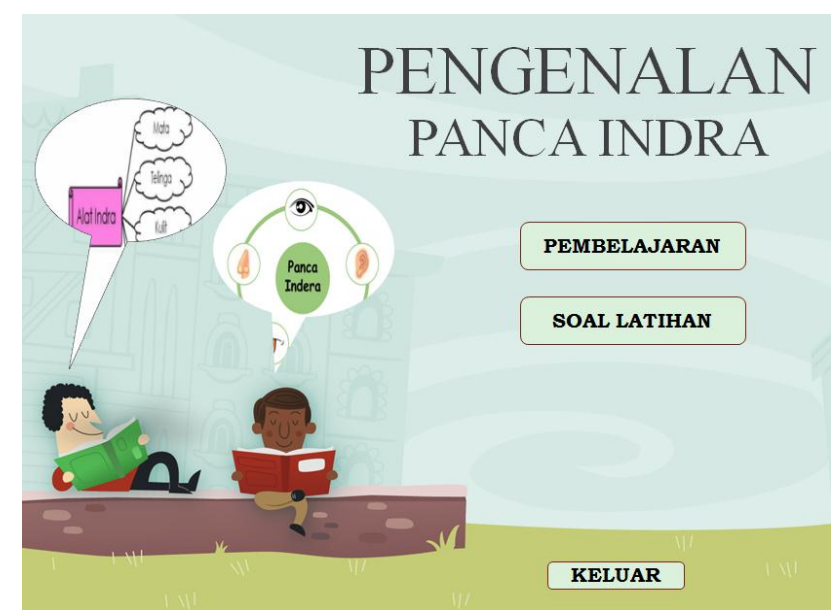

Gambar.7 Tampilan Menu Utama 


\section{PEMBELAJARAN}

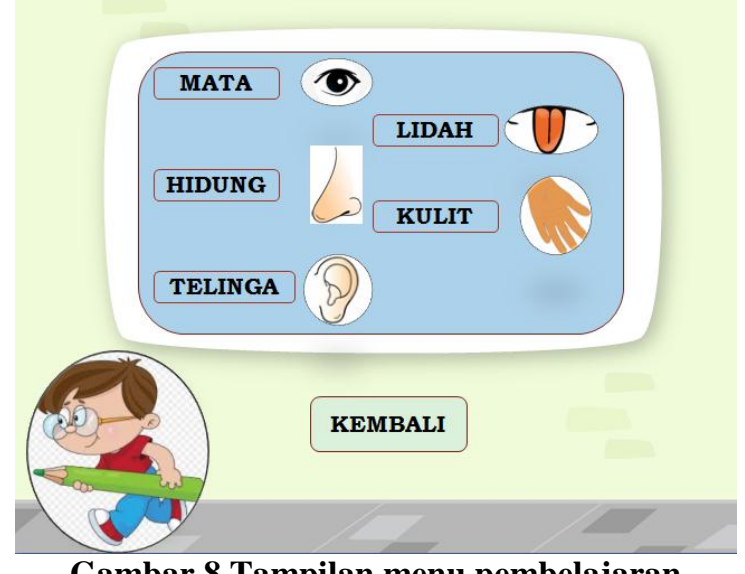

Gambar.8 Tampilan menu pembelajaran

3) Latihan Soal : Menu Latihan Soal adalah menu yang akan menampilkan soal latihan dan tombol a, b, c maupun d. Dimana tombol ini digunakan untuk memilih jawaban agar bisa melanjutkan ke pertanyaan selanjutnya dapat dilihat pada Gambar 9.

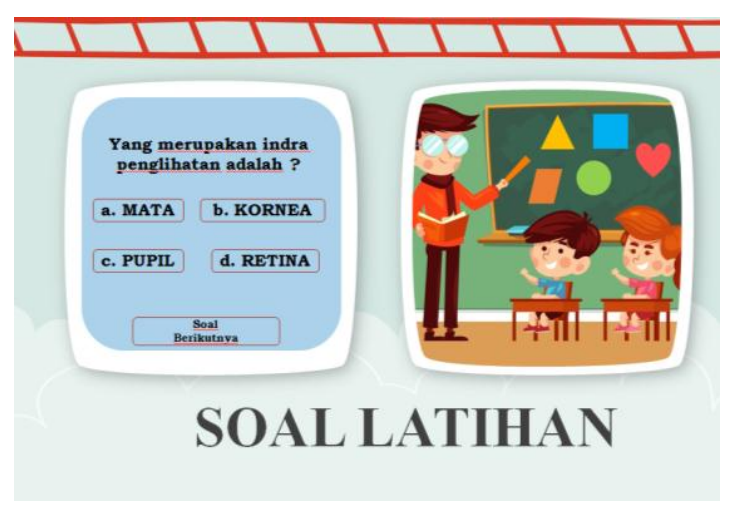

\section{Gambar.9 Tampilan menu latihan soal}

4) Hasil Latihan : Pada saat permainan berakhir, maka aplikasi akan menampilkan nilai yang diperoleh pada saat latihan soal dapat dilihat pada Gambar 10.

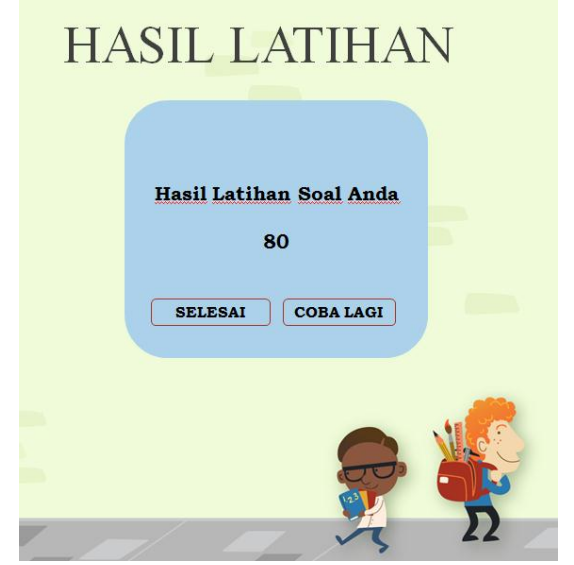

\section{Gambar.10 Tampilan menu hasil latihan soal}

\section{Pengujian}

Pengujian black box dilakukan untuk pengecekan apakah fungsi-fungsi modul dapat berjalan sebagaimana mestinya. Pengujian black box berfokus pada persyaratan fungsional perangkat lunak, pengujian ini akan menguji secara detail dari menu utama, pembelajaran, opsi belajar, belajar permenit, latihan dan nilai. Hasil yang diharapkan dari pengujian ini adalah keberhasil dan tidak ada kesalahan atau tidak berhasil, keseluruhan pengujian dapat dilihat pada Tabel I.

TABEL I

PENGUJIAN BLACK BOX

\begin{tabular}{|c|c|c|c|}
\hline Item Uji & Detail Uji & Hasil Yang Diharapkan & Hasil Pengujian \\
\hline Menu & Utama & masuk ke menu utama. & $\begin{array}{l}\square \text { Berhasil } \\
\square \text { Tidak berhasil }\end{array}$ \\
\hline Menu & Pembelajaran & $\begin{array}{l}\text { Jika tombol belajar di klik, } \\
\text { maka akan menampilkan menu } \\
\text { belajar materi jam dan waktu. }\end{array}$ & $\begin{array}{l}\square \text { Berhasil } \\
\square \text { Tidak berhasil }\end{array}$ \\
\hline Menu & Opsi Belajar & $\begin{array}{l}\text { Ketika materi di menu belajar } \\
\text { telah selesai atau jika tombol } \\
\text { next di menu belajar diklik, } \\
\text { otomatis akan menuju ke menu } \\
\text { opsi belajar. }\end{array}$ & $\begin{array}{l}\square \text { Berhasil } \\
\square \text { Tidak berhasil }\end{array}$ \\
\hline Halaman & $\begin{array}{c}\text { Belajar Per } 10 \\
\text { Menit }\end{array}$ & $\begin{array}{l}\text { Ketika tombol per } 10 \text { menit di } \\
\text { menu opsi belajar diklik, maka } \\
\text { akan menampilkan halaman } \\
\text { belajar dalam mode } 10 \text { menit. }\end{array}$ & $\begin{array}{l}\square \text { Berhasil } \\
\square \text { Tidak berhasil }\end{array}$ \\
\hline
\end{tabular}




\begin{tabular}{llll}
\hline Menu & Latihan & Jika tombol belajar di klik, & \\
& & maka akan menampilkan menu & $\square$ Berhasil \\
& latihan soal acak. & $\square$ Tidak berhasil \\
Halaman & Ketika user menyelesaikan 10 & \\
& soal yang terdapat di menu & \\
& latihan, maka otomatis akan & \\
& menuju ke halaman score yang $\quad \square$ Berhasil \\
& terdapat score dan bintang $\quad \square$ Tidak berhasil \\
& sesuai dengan kemampuan user \\
& menjawab soal. \\
\hline
\end{tabular}

\section{IV.PENUTUP}

\section{A. Kesimpulan}

Dapat disumpulkan bahwa media pembelajaran ini menjelaskan pengetahuan tentang organ tubuh manusia, seperti bagian tubuh mana sajakah yang termaksud dengan panca indra. Media pembelajaran menggunakan algoritma suffle random yang berfungsi untuk mengacak posisi soal, agar pemain tidak mengingat urutan soal dalam permainan. Hasil akhirnya sebelum digunakan oleh para siswa, dilakukan pengujian black box, dengan menguji apakah fungsi-fungsi dalam aplikasi tersebut berjalan dengan baik.

\section{B. Saran}

Diharapkan aplikasi ini dapat diperbaiki dan dikembangkan dengan penambahan fitur misalnya penambahan menu cara menggunakan aplikasi dan audio, sehingga media pembelajaran ini dapat terlihat lebih menarik, soal latihan ditambah, dibuat berbeda, dilengkapi pembahasan soal jika terjadi kesalahan dan menu belajar dibuat lebih berfariasi. Diharapkan para siswa memahami panca indra serta bagian-bagianya melalui soal-soal latihan yang ada,

\section{DAFTAR PUSTAKA}

[1] R. Andrea, "Teknik Pengacakan Posisi Objek Permainan Match-Up "Find Me!-Bumi Etam," Semnasteknomedia Online, vol. 3 No 1, hlm. 5-7, 2009.
[2] Warsita, Teknologi Pembelajaran, Landasan dan Aplikasinya. Jakarta: Rineka Cipta, 2008.

[3] Munir, Mata pelajaran Berbasis Teknologi Informasi dan Komunikasi. Bandung: CV.Alvabet, 2008.

[4] L. Stefany, S. M. Sari, dan S. M. Frans, "Implemtasi Pengalaman Panca Indra pada Interior Restoran Bentoyo di Surabaya," Intra, vol. 5 No 2, hlm. 81-87, 2017.

[5] M. C. Legawaputri, S. M. Sari, dan C. J. Pradjonggo, "Implementasi Pengalaman Panca Indra pada Interior Restoran Shao Kao Surabaya," Intra, vol. 6 no 2, hlm. 786-791, 2018.

[6] Sudaryanto dan M. Ikhwandi, "Penerapan Ojs dalam Mobile/android yang Diperuntukkan Bagi Pembaca dan Author," Compiler, vol. 6 No 2, hlm. 37-48, 2017.

[7] I. Binanto, Multimedia Digital Dasar Teori dan Pengembangannya. Yogyakarta, 2010.

[8] A. Yusnita, A. Y. Rangan, dan F. Setiawan, "Membangun Game Fun Animal Puzzle Menggunakan Algoritma Shuffle Random," Sebatik, vol. 15 No 1, hlm. 1-6, 2016.

[9] A. Yusnita, S. Wijayanti, dan P. A. Felita, "Implementasi Algoritma Shuffle Random Pada Edugame Magic Time Berbasis Universal Windows Platform (Uwp),", Pros. Snitt Poltekba, vol. 2 no 1, hlm. 203-208, 2017.

[10] W. Sulistio, "Penerapan Metode Shuffle Random pada Aplikasi Multimedia Pembelajaran Panca Indra Tingkat SD Berbasis Android," Skripsi, Teknik Informatika, STMIK Widya Cipta Dharma, 2018. 